\title{
Application of quality improvement strategies in 389 European hospitals: results of the MARQulS project
}

\author{
M J M H Lombarts, ${ }^{1}$ I Rupp,, ${ }^{1}$ P Vallejo, ${ }^{2}$ R Suñol, ${ }^{2}$ N S Klazinga'
}

${ }^{1}$ Academic Medical Center, Department of Social Medicine, University of Amsterdam, Amsterdam, the Netherlands: ${ }^{2}$ Avedis Donabedian Institute, Autonomous University of Barcelona, and CIBER Epidemiology and Public Health (CIBERESP), Barcelona, Spain

Correspondence to: Dr M J M H (Kiki) Lombarts, Academic Medical Center Department of Social Medicine, University of Amsterdam,

Meibergdreef 9, P0 Box 22700,

$1100 \mathrm{DE}$ Amsterdam, the

Netherlands; m.j.lombarts@ amc.uva.nl

Accepted 12 November 2008

\section{UNIOCKFI)}

This paper is freely available online under the BMJ Journals unlocked scheme, see http:// qshc.bmi.com/info/unlocked.dtl

\section{ABSTRACT}

Context: This study was part of the Methods of Assessing Response to Quality Improvement Strategies (MARQulS) research project investigating the impact of quality improvement strategies on hospital care in various countries of the European Union (EU), in relation to specific needs of cross-border patients.

Aim: This paper describes how EU hospitals have applied seven quality improvement strategies previously defined by the MARQulS study: organisational quality management programmes; systems for obtaining patients' views; patient safety systems; audit and internal assessment of clinical standards; clinical and practice guidelines; performance indicators; and external assessment. Methods: A web-based questionnaire was used to survey acute care hospitals in eight EU countries. The reported findings were later validated via on-site survey and site visits in a sample of the participating hospitals. Data collection took place from April to August 2006.

Results: 389 hospitals participated in the survey; response rates varied per country. All seven quality improvement strategies were widely used in European countries. Activities related to external assessment were the most broadly applied across Europe, and activities related to patient involvement were the least widely implemented. No one country implemented all quality strategies at all hospitals. There were no differences between participating hospitals in western and eastern European countries regarding the application of quality improvement strategies.

Conclusions: Implementation varied per country and per quality improvement strategy, leaving considerable scope for progress in quality improvements. The results may contribute to benchmarking activities in European countries, and point to further areas of research to explore the relationship between the application of quality improvement strategies and actual hospital performance.

Quality and safety of patient care are high on the European policy agenda, as evidenced by various commitments by European health ministries. Patient mobility has clearly been a triggering factor. Governments may fear that differences in the perceived quality or costs of health services may encourage patients to cross borders to obtain healthcare. ${ }^{1-3}$ The fact that member states are now talking about what is still their responsibility has increased the need for information about the crossborder movement. The Methods of Assessing Response to Quality Improvement Strategies (MARQuIS) research project aims to be instrumental in providing a better understanding of this movement, by investigating and comparing different quality improvement (OI) strategies in healthcare systems across the European Union.
In this article we focus on the degree to which OI strategies are applied at European hospitals, by their own report. As presented in the Health Care Quality Strategies in Europe study, we identified seven national OI strategies. ${ }^{45}$ Our primary focus is on implementation of the strategies at the $\mathrm{EU}$ level; data at the country level are reported for reference purposes. The OI strategies we investigated were:

- organisational quality management programmes;

- systems for obtaining patients' views;

- patient safety systems;

- audit and internal assessment of clinical standards;

- clinical and practice guidelines;

- performance indicators and measurements;

- external assessment.

The countries participating in this study were Spain, France, Poland, Czech Republic, the UK, Ireland, Belgium and the Netherlands.

\section{MATERIAL AND METHODS}

\section{Questionnaire design}

We conducted a web-based questionnaire survey. The questionnaire was developed to measure OI, defined as the application of quality policies and procedures, quality governance structures, and quality activities used to close the gap between current and expected levels of quality. ${ }^{4}$ To determine the distinctive aspects of OI we used several sources, such as existing OI questionnaires, ${ }^{6-9}$ a review of the quality literature, ${ }^{10-12}$ an analysis of accreditation manuals, ${ }^{11} 1314$ and the results of previous MARQuIS studies including a literature review covering OI strategies in member states of the EU, and an analytical framework defining areas of $\mathrm{OI}$ policies and strategies. A glossary of quality concepts and tools was made available to participants.

The questionnaire consisted of four sections: one section focused on OI at the hospital level, the other three on quality management for specific medical conditions. The three medical conditions for focused data collection were selected based on two criteria: the condition had to represent a significant volume of cross-border patient care,$^{15}$ and the combination of conditions was intended to cover the most relevant services offered by a hospital-that is, emergency surgical and medical services, and maternal and neonatal services. The three conditions selected were acute myocardial infarctions (AMI), acute appendicitis and deliveries. For each condition selected, the literature was searched for specific OI strategies. Search terms 
used included "quality assurance", "quality improvement", "quality assessment", and "performance measurement". ${ }^{16-31} \mathrm{We}$ stopped searching when additional publications no longer resulted in new relevant OI strategies, activities or measures. Practising medical specialists were consulted for their comments and suggestions on the specific OI strategies, activities, and measures (see Acknowledgements).

Both members of the MARQuIS team and the nine country coordinators reviewed the draft questionnaire. (For Belgium two country coordinators were appointed, one for Flemish-speaking and one for French-speaking hospitals.) The questionnaire was then pilot tested in two hospitals in Ireland and the UK (these countries were chosen for language-related reasons), and a few amendments were made as a result. The questionnaire was translated into five languages (Spanish, French, Polish, Czech, and Dutch); the country coordinators were responsible for translation. A forward-backward translation protocol was used. Figure 1 shows the final structure of the questionnaire, which totalled 199 questions. For each of the four sections a preferred respondent (at the senior level) was suggested.

\section{Response categories}

Various scoring scales were used depending on the type of question. Items were scored on a two-point scale (yes/no), a four-point scale (see tables 2 to 8 in Results), or a five-point Likert scale $(1=$ strongly agree, $5=$ strongly disagree $)$.

\section{Sampling and recruitment}

Our survey focused on European hospitals with a minimum of 100 acute care beds, and offering care for at least two out of the three conditions selected for study (AMI, appendicitis and deliveries). Two additional criteria defined the hospital sample: ownership status (public, private not-for-profit and private forprofit), and actual or potential cross-border care delivery. ${ }^{31}$ The target was to include a total of 600 hospitals covering eight countries. For smaller countries (Belgium, the Netherlands, Ireland, Czech Republic) this meant that all hospitals meeting the inclusion criteria were invited to participate. In the remaining countries, hospitals were randomly sampled from a list of hospitals that met the sampling criteria. Hospital recruitment was done by the country coordinators, who used different strategies. To make participation more appealing to

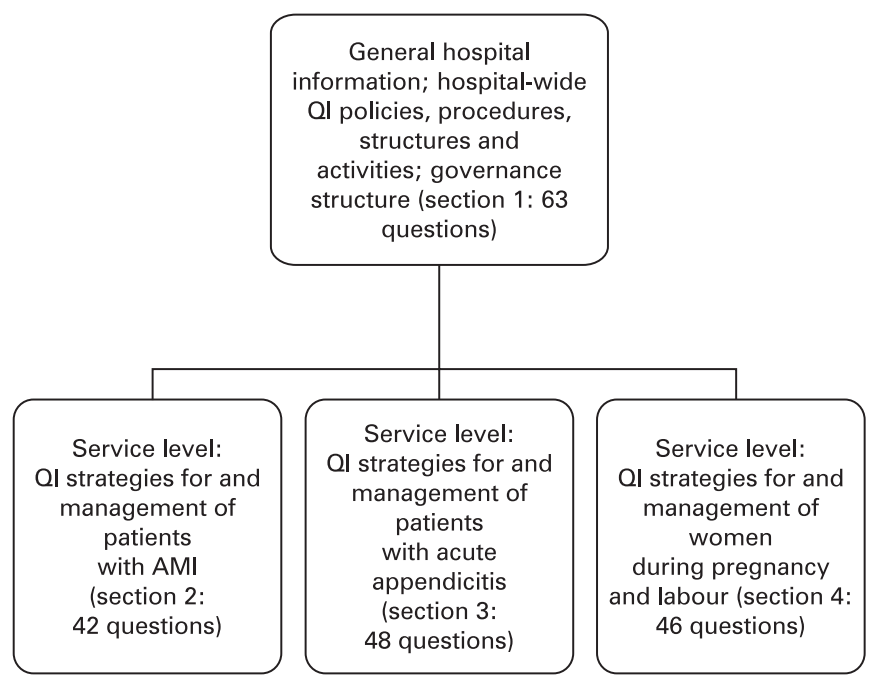

Figure 1 Structure of the MARQulS questionnaire. AMI, acute myocardial infarction; Ol, quality improvement. hospitals, a package of advantages was offered to the hospitals, including membership in the MARQuIS network, a certificate of participation, and free subscription to the project's newsletter. Hospitals that agreed to participate in the survey received an e-mail inviting them to enter the MARQuIS website (http:// www.marquis.be) and fill out the web-based questionnaire. Upon request, a paper version of the questionnaire could be used and sent to the researchers (MJMHL or IR). Data were collected from the beginning of April to the end of August 2006. Hospitals received up to three reminders. Again, country coordinators used different approaches to raise the response rates.

\section{Validation of the data}

To validate the questionnaire data, two analyses were performed by using data collected during on-site hospital visits in a selected sample of 89 hospitals that had previously completed the questionnaire. Visits were performed by independent external auditors. All aspects of on-site visits are described in detail elsewhere. ${ }^{32}$

During the visits, the hospitals' key informants were asked to answer 25 questions that had been previously asked in the questionnaire. The reliability of the questionnaire was assessed by the level of agreement between the responses to these 25 questions as given in the questionnaire and during the on-site visits. In addition, for 14 of these 25 questions the external auditors requested evidence to check the answers given during the audit. Criterion validity was then assessed as the degree of agreement between the information provided by key informants and the evidence found to underpin this information. Reliability and validity were assessed as the index of expected agreement, which is the proportion of cases in which the results of both assessments matched. ${ }^{33}$

\section{RESULTS}

\section{Response rates and study population}

The country coordinators approached a total of 1396 hospitals, of which 483 visited the web-based questionnaire and ultimately 389 submitted the completed questionnaire (table 1). Response rates varied per country. The study population consisted of public ( $80 \%$ ) as well as private $(20 \%)$ hospitals, and included university (23.5\%), teaching (48.9\%) and nonteaching hospitals $(27.6 \%)$. The mean number of sites per hospital was 2.46. Almost a quarter of all hospitals were considering collaboration to deliver cross-border patient care, but few hospitals were doing so at the time of the study. ${ }^{15}$

Table 1 Hospital recruitment and response rates by country

\begin{tabular}{lccc}
\hline & $\begin{array}{l}\text { Hospitals } \\
\text { approached }\end{array}$ & $\begin{array}{l}\text { Hospitals entering } \\
\text { web-based } \\
\text { questionnaire }\end{array}$ & $\begin{array}{l}\text { Hospitals } \\
\text { concluding web- } \\
\text { based } \\
\text { questionnaire }\end{array}$ \\
\hline UK & 250 & 41 & 14 \\
Ireland & 44 & 29 & 25 \\
The Netherlands & 97 & 12 & 10 \\
Belgium & 45 & 33 & 25 \\
France & 322 & 100 & 78 \\
Spain & 307 & 131 & 113 \\
Poland & 250 & 84 & 80 \\
Czech Republic & 81 & 53 & 44 \\
Total & 1396 & 483 & 389
\end{tabular}




\section{Results of the validation process}

Regarding reliability, comparison of the information obtained for 25 items from questionnaires and on-site visits resulted in the following ranges of agreement: for five items agreement was over $90 \%$, for 12 items the level of agreement was $>70 \%$ and $<90 \%$, and for eight items agreement was $<70 \%$. Given the period of 7-9 months between the questionnaire and the on-site visits, it is likely that at least some of the items studied had actually changed. In addition, the 14 items analysed to assess criterion validity resulted in the following levels of agreement: seven items had an agreement index of $>90 \%$, six items rated $>70 \%$ and $<90 \%$, and one item scored an index of $<70 \%$. Based on these results, we considered the information collected with the questionnaire a fair approximation of the actual situation at participating hospitals.

\section{Ql strategies}

A previous MARQuIS study ${ }^{34}$ identified seven mandatory OI strategies for hospitals. The extent to which these strategies are applied at European hospitals is reported below.

\section{Ol strategy 1: Organisational quality management programmes}

Hospitals reported using quality management programmes in developing and implementing OI (table 2). Overall, the International Organization for Standardization (ISO) 9000 management system standards were used most often, and the European Foundation for Quality Management (EFOM) model was used least often. However, there were wide variations between countries. Belgium was the only country where the EFOM model was preferred by most hospitals (60.9\%); in all other countries the ISO system was the dominant scheme. In Poland (50.0\%), the Czech Republic (59.5\%), and Spain $(70.3 \%)$ the use of ISO was widespread. In Spain some hospitals seemed to use both schemes. Irish hospitals reported moderate use of a quality management programme (ISO $=31.6 \%$, EFOM 20.0\%), but stressed the systematic use of specific OI teams in most of their hospital departments, either systematically (47.8\%) or unsystematically $(17.4 \%)$. French hospitals relied least on the programmatic approach with the ISO (28.6\%) or EFOM system (3.4\%), and the availability if OI teams was limited $(27.7 \%)$.

Responsibilities for, and policies on, blood transfusion, the use of antibiotics, and hospital infection control were clearly assigned to a committee or person in almost all hospitals across Europe, with the exception of Czech hospitals, which reported significantly less clear organisation for all three hospital-wide functions. Spanish hospitals showed a gap in organising responsibilities for blood transfusion (87.5\%), and Irish hospitals in the use of antibiotics (87\%). Responsibility for the prevention of bed sores seemed less structured within European hospitals, varying from a reported $66.7 \%$ in Ireland to $95.8 \%$ in Belgium.

\section{Ol strategy 2: Systems for obtaining patients' views}

Monitoring the views of patients by systematically conducting patient surveys was a common practice in $64.5 \%$ of the participating European hospitals. The Czech Republic stood out, reporting that $91.9 \%$ of their hospitals systematically monitored patient views. These numbers refer to hospital-wide systems for collecting patients' views on the care they received. At the department level, patients are asked at discharge for their opinion on the quality of care delivered by the hospital staff. In France this strategy was widely implemented, with approximately $65 \%$ of the hospitals reporting a policy to measure patients' opinion at discharge. In Poland, this was a common practice in less than $14 \%$ of the hospitals. The rates varied significantly for the three medical conditions included in our study, and variation between countries seemed greater than within countries (table 3).

Across participating European hospitals, patient involvement seemed to be little developed. Hospitals were asked to identify the activities in which individual patients or patient organisations were always or almost always involved. Participation in the design of protocols or the development of standards was reported by $3 \%$ to $4 \%$ of all hospitals; participation in improvement projects or in quality committees was reported by less than $10 \%$. Patient involvement was best implemented in France, with almost $40 \%$ of the hospitals reporting that they

Table 2 Quality improvement (Ol) strategies as applied in European hospitals: organisational quality management programmes/activities; total and per country*, numbers are positive responses in valid percentages (total item response in absolute numbers)

\begin{tabular}{|c|c|c|c|c|c|c|c|}
\hline Specification of ol strategy & Total & Ireland & Belgium & France & Spain & Poland & $\begin{array}{l}\text { Czech } \\
\text { Republic }\end{array}$ \\
\hline $\begin{array}{l}\text { The use of ISO in implementing a } \\
\text { quality system }\end{array}$ & $51.2(336)$ & $31.6(19)$ & $21.7(23)$ & $28.6(63)$ & $70.3(101)$ & $50.0(76)$ & $59.5(37)$ \\
\hline $\begin{array}{l}\text { The use of EFOM in implementing a } \\
\text { quality system }\end{array}$ & $29.5(319)$ & $20.0(20)$ & $60.9(23)$ & $3.4(59)$ & $57.4(101)$ & $4.3(69)$ & $20.0(30)$ \\
\hline $\begin{array}{l}\text { Active quality improvement team(s)/ } \\
\text { circles } \dagger\end{array}$ & 349 & 23 & 24 & 65 & 106 & 76 & 37 \\
\hline 1 & 27.5 & 47.8 & 4.2 & 7.7 & 19.8 & 42.1 & 48.6 \\
\hline 2 & 17.5 & 17.4 & 41.7 & 20.0 & 16.0 & 14.5 & 13.5 \\
\hline 3 & 38.1 & 30.4 & 29.2 & 47.7 & 53.8 & 23.7 & 13.5 \\
\hline 4 & 13.2 & 4.3 & 25.0 & 23.1 & 8.5 & 9.2 & 21.6 \\
\hline \multicolumn{8}{|l|}{ Committee or person responsible for: } \\
\hline Hospital infections control & $98.9(353)$ & $100(25)$ & $100(24)$ & $100(78)$ & $100(107)$ & $100(80)$ & $89.5(38)$ \\
\hline Blood transfusion & $92.2(348)$ & $100(25)$ & $100(24)$ & $100(78)$ & $87.5(104)$ & $92.1(76)$ & $78.9(38)$ \\
\hline Prevention of bed sores & $85.3(346)$ & $66.7(21)$ & $95.8(24)$ & $79.7(64)$ & $94.2(104)$ & $78.9(76)$ & $84.6(39)$ \\
\hline Policy on use of antibiotics & $92.6(352)$ & $87.0(23)$ & $95.8(24)$ & $96.9(65)$ & $98.1(106)$ & $96.1(76)$ & $66.7(39)$ \\
\hline
\end{tabular}


Table 3 Quality improvement (QI) strategies as applied in European hospitals: systems for getting the views of patients (total and per country, numbers are valid percentages $\dagger$ )

\begin{tabular}{|c|c|c|c|c|c|c|c|}
\hline Specification of ol strategy & Total & Ireland & Belgium & France & Spain & Poland & $\begin{array}{l}\text { Czech } \\
\text { Republic }\end{array}$ \\
\hline 1 & 64.5 & 54.5 & 60.9 & 56.1 & 67.3 & 61.3 & 91.9 \\
\hline 3 & 15.7 & 27.3 & 13.0 & 21.2 & 16.3 & 16.0 & 0 \\
\hline 4 & 4.7 & 0 & 8.7 & 7.6 & 4.8 & 5.3 & 0 \\
\hline Analysis of patient complaints ( $n=350$ ) & 350 & 23 & 24 & 66 & 106 & 73 & 38 \\
\hline 3 & 5.4 & 8.7 & 4.2 & 9.1 & 5.7 & 5.3 & 0 \\
\hline 4 & 1.7 & 4.3 & 4.2 & 1.5 & 2.8 & 0 & 0 \\
\hline \multicolumn{8}{|l|}{ Patient involvement int: } \\
\hline Discussing the results of patient surveys and complaints handling $(n=345)$ & 345 & 23 & 24 & 63 & 105 & 75 & 38 \\
\hline 1 & 7.2 & 4.3 & 0 & 20.6 & 1.9 & 4.0 & 7.9 \\
\hline 2 & 6.7 & 4.3 & 8.3 & 19.0 & 1.0 & 4.0 & 2.6 \\
\hline 2 & 2.3 & 8.7 & 0 & 2.3 & 0 & 4.0 & 0 \\
\hline 3 & 16.1 & 34.8 & 16.7 & 16.9 & 7.5 & 9.3 & 10.5 \\
\hline 4 & 73.6 & 52.2 & 70.8 & 72.3 & 86.8 & 77.3 & 76.3 \\
\hline Designing protocols $(n=345)$ & 345 & 22 & 24 & 65 & 104 & 75 & 38 \\
\hline 1 & 1.2 & 0 & 0 & 0 & 0 & 2.7 & 5.3 \\
\hline 2 & 1.7 & 4.5 & 0 & 3.1 & 0 & 2.7 & 0 \\
\hline 3 & 15.1 & 27.3 & 8.3 & 24.6 & 8.7 & 6.7 & 0 \\
\hline 4 & 76.5 & 63.6 & 83.3 & 70.8 & 86.5 & 77.3 & 89.5 \\
\hline The evaluation of achieving quality objectives ( $n=347)$ & 347 & 23 & 24 & 66 & 104 & 75 & 38 \\
\hline 1 & 4.9 & 0 & 8.3 & 6.1 & 1.0 & 8.0 & 5.3 \\
\hline 2 & 7.2 & 13.0 & 8.3 & 9.1 & 1.9 & 10.7 & 2.6 \\
\hline 3 & 20.5 & 56.5 & 16.7 & 40.9 & 8.7 & 8.0 & 7.9 \\
\hline 2 & 5.8 & 9.1 & 0 & 10.6 & 1.9 & 6.8 & 0 \\
\hline 3 & 27.5 & 40.9 & 22.7 & 53.0 & 21.4 & 13.5 & 5.3 \\
\hline 4 & 57.0 & 36.4 & 68.2 & 30.3 & 67.0 & 68.9 & 81.6 \\
\hline $\begin{array}{l}\text { Patients' opinion about quality of care asked at discharge } \\
\text { (for patients with acute myocardial infarction) }(n=319)\end{array}$ & 319 & 22 & 24 & 49 & 102 & 69 & 37 \\
\hline 1 & 34.5 & 22.7 & 37.5 & 69.4 & 39.2 & 8.7 & 40.5 \\
\hline 2 & 15.4 & 13.6 & 12.5 & 12.2 & 12.7 & 15.9 & 27.0 \\
\hline 3 & 23.8 & 18.2 & 37.5 & 8.2 & 22.5 & 24.6 & 29.7 \\
\hline 4 & 20.7 & 31.8 & 8.3 & 6.1 & 22.5 & 43.5 & 2.7 \\
\hline $\begin{array}{l}\text { Patients' opinion about quality of care asked at discharge } \\
\text { (for patients with appendicitis) }(n=313)\end{array}$ & 313 & 22 & 21 & 51 & 100 & 71 & 34 \\
\hline 1 & 39.6 & 22.7 & 47.6 & 76.5 & 44.0 & 8.5 & 47.1 \\
\hline 2 & 14.7 & 18.2 & 4.8 & 13.7 & 10.0 & 19.7 & 17.6 \\
\hline 3 & 19.8 & 18.2 & 23.8 & 3.9 & 24.0 & 21.1 & 20.6 \\
\hline 4 & 19.2 & 22.7 & 14.3 & 2.0 & 21.0 & 36.6 & 11.8 \\
\hline $\begin{array}{l}\text { Patients' opinion about quality of care asked at discharge } \\
\text { (patients at maternal service) }(n=301)\end{array}$ & 301 & 18 & 24 & 50 & 87 & 73 & 34 \\
\hline 1 & 44.9 & 27.8 & 41.7 & 50.0 & 44.8 & 24.7 & 50.0 \\
\hline 2 & 14.6 & 11.1 & 16.7 & 11.8 & 14.9 & 20.5 & 11.8 \\
\hline 3 & 14.0 & 11.1 & 16.7 & 23.5 & 14.9 & 15.1 & 23.5 \\
\hline 4 & 15.3 & 22.2 & 20.8 & 2.9 & 17.2 & 24.7 & 2.9 \\
\hline
\end{tabular}

*The results for the UK and the Netherlands are included in the total but not listed separately, due to the very low response rates. $\dagger$ The sum of percentages may not always equal $100 \%$; the percentage answers "don't know/no answer" are not listed here. $1=$ yes, in most departments ( $>50 \%) ; 2=$ yes, in most departments (>50\%), but not systematically; $3=$ yes, in some departments $(<50 \%) ; 4=$ no. $\$$ From this point on the answer categories $1-4$ should be read as: $1=$ yes always; $2=$ most of the time; $3=$ sometimes; $4=$ no. 


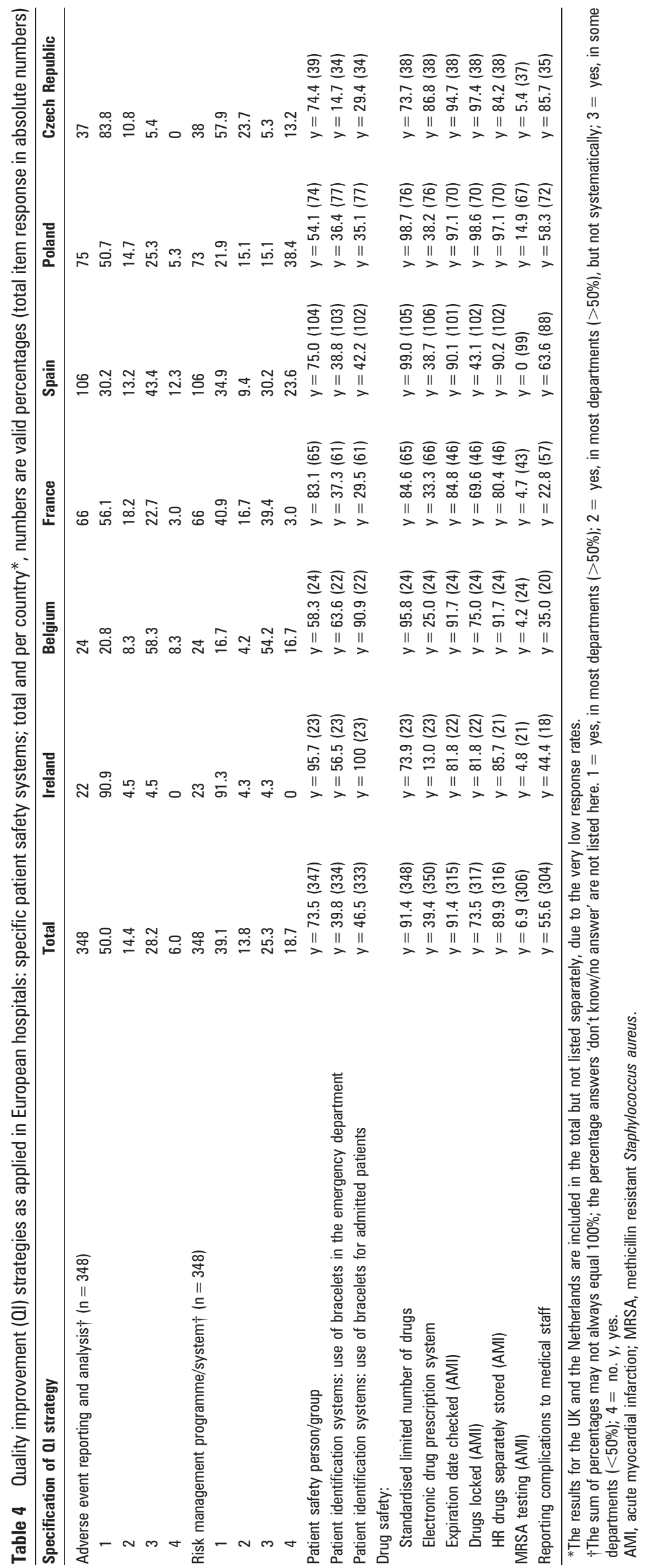


Table 5 Quality improvement (Ql) strategies as applied in European hospitals: clinical and practice guidelines; total and per country*, numbers are positive responses in valid percentages (total item response in absolute numbers)

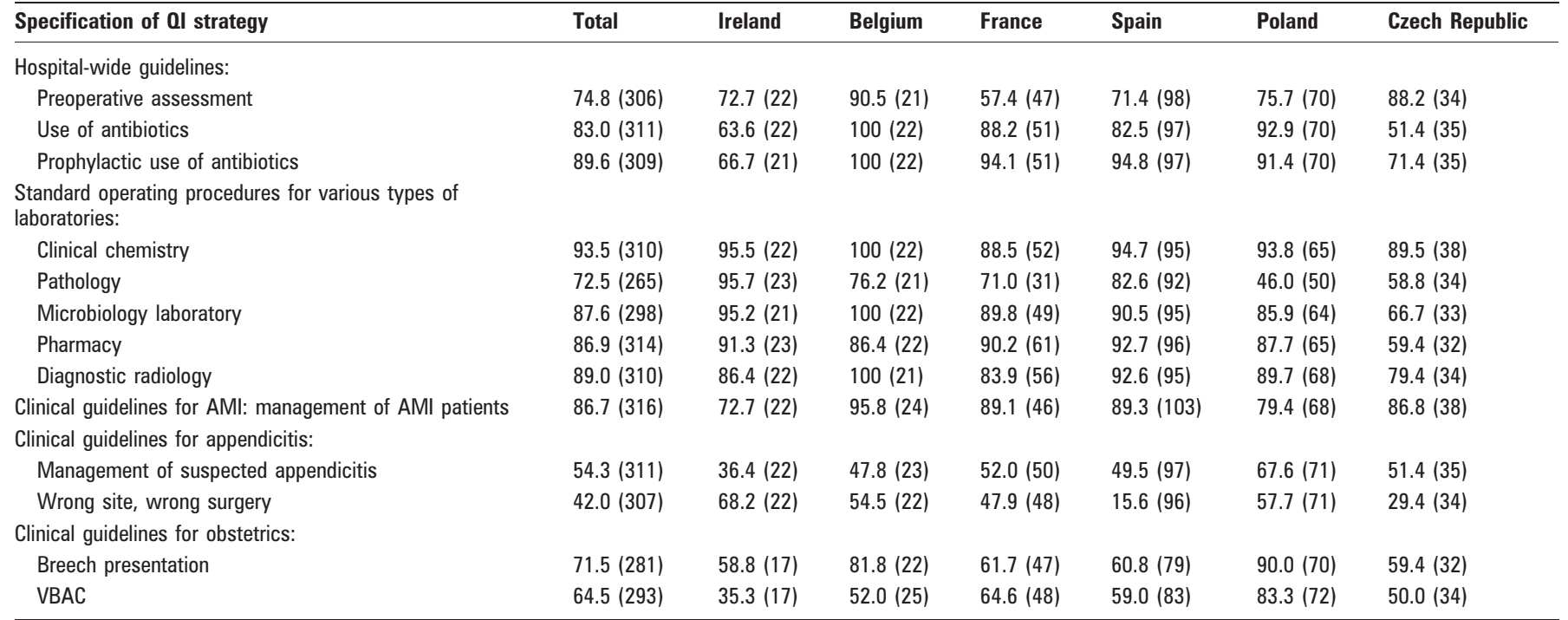

*The results for the UK and the Netherlands are included in the total but not listed separately, due to the very low response rates.

AMI, acute myocardial infarction; VBAC, vaginal birth after caesarean section.

involved patients in the discussion of the results of patient surveys or complaints, and $32 \%$ stating that patients participated in quality committees.

\section{Ol strategy 3: Patient safety systems}

Hospitals were asked how patient safety was organised and managed, whether the results were reported, and if so, how they were reported (table 4). Responsibility for patient safety was assigned to a committee or person in approximately $75 \%$ of the hospitals. At $39.1 \%$ of the hospitals a risk management programme or system was in place; $50 \%$ of the hospitals systematically reported and analysed adverse events, and $55.6 \%$ also reported complications to the medical staff. These are average numbers for Europe; variation between countries was substantial. Irish hospitals scored consistently high (>90\%), and Belgium and Spanish hospitals relatively low on the availability of safety systems.

Specific safety questions addressed drug safety management and patient identification. In general, drug safety seemed to be assured in all participating hospitals: the use of drugs was standardised and controlled, and systems for storing, checking and preventing unauthorised access to drugs seemed well implemented. Electronic drug prescriptions were used widely only in Czech hospitals (86.8\%). By comparison, in Ireland a

Table 6 Quality improvement (OI) strategies as applied in European hospitals: performance indicators or measures; total and per country* , numbers are positive responses in valid percentages (total item response in absolute numbers)

\begin{tabular}{|c|c|c|c|c|c|c|c|}
\hline Specification of 0 l strategy & Total & Ireland & Belgium & France & Spain & Poland & Czech Republic \\
\hline \multicolumn{8}{|l|}{ Availability of AMI performance indicators: } \\
\hline Door-to-needle time & $57.7(291)$ & $68.2(22)$ & $62.5(24)$ & $45.2(42)$ & $62.0(92)$ & $51.6(64)$ & $55.9(34)$ \\
\hline Receipt of reperfusion & $70.3(293)$ & $54.5(22)$ & $75.0(24)$ & $61.4(44)$ & $66.7(93)$ & $79.4(63)$ & $76.5(34)$ \\
\hline Aspirin use $<24 \mathrm{~h}$ & $71.8(291)$ & $68.2(22)$ & $79.2(24)$ & $59.1(44)$ & $69.2(91)$ & $82.5(63)$ & $70.6(34)$ \\
\hline Prescription ACE inhibitors at discharge & $67.5(292)$ & $63.6(22)$ & $73.9(23)$ & $53.5(43)$ & $59.1(93)$ & $84.4(64)$ & $67.6(34)$ \\
\hline Prescription of $\beta$-blockers at discharge & $71.2(288)$ & $63.6(22)$ & $73.9(23)$ & $51.2(43)$ & $69.6(92)$ & $87.3(63)$ & $71.9(32)$ \\
\hline Prescription of aspirin at discharge & $73.6(288)$ & $68.2(22)$ & $83.3(24)$ & $58.1(43)$ & $71.4(91)$ & $85.5(62)$ & $69.7(33)$ \\
\hline Inpatient mortality & 74.4 (289) & $57.1(21)$ & $79.2(24)$ & $54.8(42)$ & $87.0(92)$ & $77.4(62)$ & $70.6(34)$ \\
\hline \multicolumn{8}{|c|}{ Availability of performance indicators for the management of appendicitis: } \\
\hline Prophylactic antibiotics & $53.8(290)$ & $33.3(21)$ & $43.5(23)$ & $43.2(44)$ & $65.2(92)$ & $73.5(68)$ & $13.3(30)$ \\
\hline Negative appendectomy & $46.5(288)$ & $33.3(21)$ & $43.5(23)$ & $42.2(45)$ & $45.1(91)$ & $53.0(66)$ & $50.0(30)$ \\
\hline Rate of lap versus open appendectomy & $51.0(286)$ & $47.6(21)$ & $60.9(23)$ & $62.2(45)$ & $58.7(92)$ & $21.5(65)$ & $64.3(28)$ \\
\hline Perforated appendicitis operated $24 \mathrm{~h}$ after admittance & $42.0(283)$ & $20.0(20)$ & $39.1(23)$ & $29.5(44)$ & $40.7(91)$ & $50.8(63)$ & $56.7(30)$ \\
\hline Wound infections & $68.2(280)$ & $50.0(20)$ & $47.8(23)$ & $47.7(44)$ & $77.8(90)$ & $75.4(61)$ & $80.0(30)$ \\
\hline \multicolumn{8}{|l|}{ Availability of performance indicators for deliveries: } \\
\hline Induced labour rate & $67.5(280)$ & $58.8(17)$ & $75.0(20)$ & $61.7(47)$ & $60.5(81)$ & $76.8(69)$ & $62.5(32)$ \\
\hline$\%$ Caesarean sections of total deliveries & $85.3(278)$ & $64.7(17)$ & $90.0(20)$ & $83.7(49)$ & $87.7(81)$ & $91.0(67)$ & $74.2(31)$ \\
\hline VBAC rate & $54.0(274)$ & $35.3(17)$ & $50.0(20)$ & $44.7(47)$ & $55.8(77)$ & $67.6(68)$ & $51.6(31)$ \\
\hline Deliveries with peridural anaesthesia & $71.9(278)$ & $52.9(17)$ & $85.0(20)$ & $83.3(48)$ & $81.3(80)$ & $58.8(68)$ & $54.8(31)$ \\
\hline
\end{tabular}

\footnotetext{
*The results for the UK and the Netherlands are included in the total but not listed separately, due to the very low response rates.
}

$\mathrm{AMI}$, acute myocardial infarction; VBAC, vaginal birth after caesarean section. 


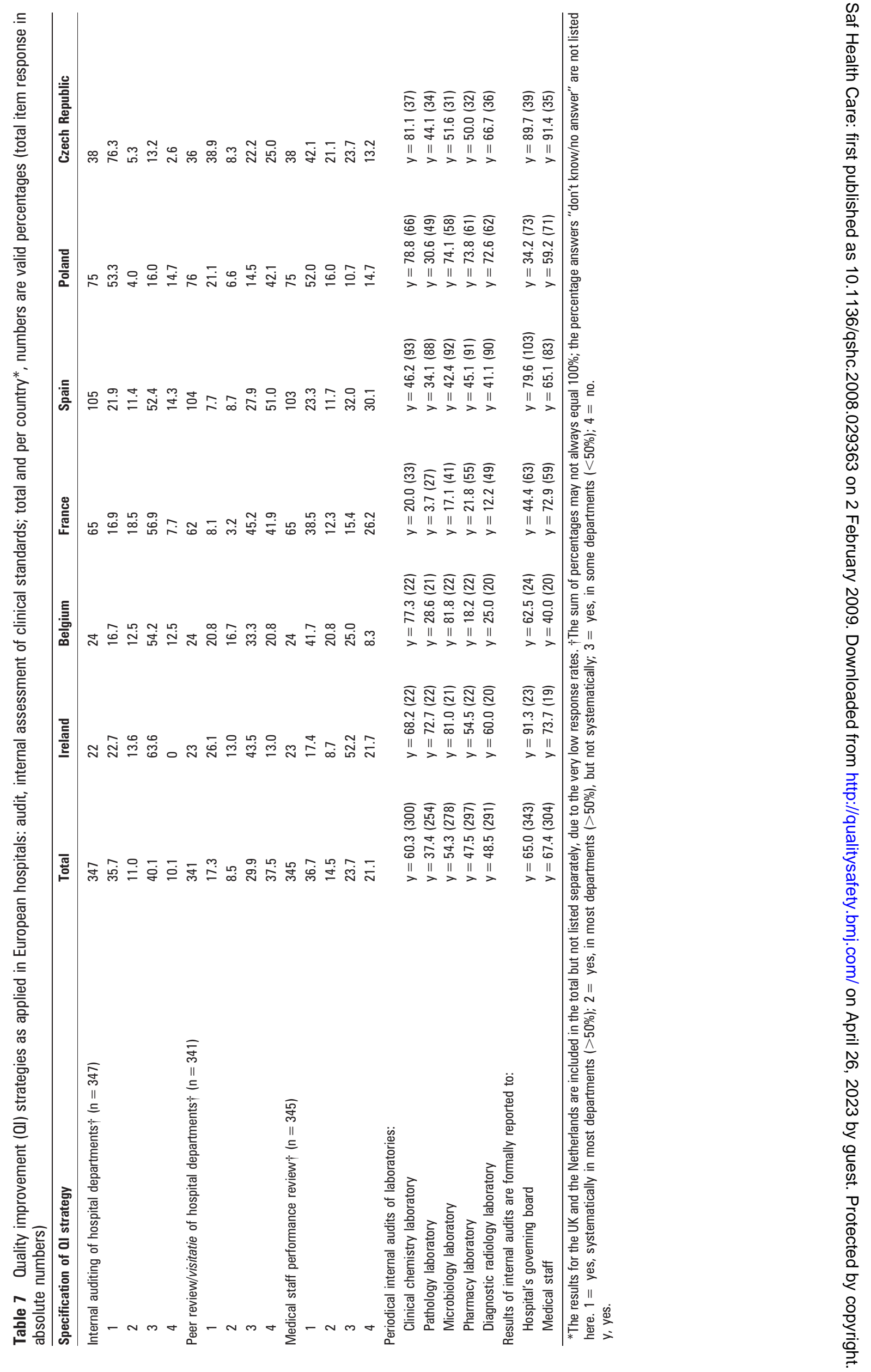


mere $13 \%$ of the hospitals reported use of electronic prescriptions. For patient identification systems the findings were the opposite, with $100 \%$ of Irish versus $29.4 \%$ of Czech hospitals using bracelets to identify admitted patients.

\section{Ol strategy 4: Clinical guidelines}

Clinical guidelines were widely used at participating European hospitals. Hospital-wide guidelines for preoperative assessment and prophylactic antibiotic use were in place in the vast majority (75-90\%) of hospitals. In the Czech Republic and Ireland, guidelines for prophylactic antibiotic use were least widely used, versus 100\% coverage in Belgian hospitals.

Laboratory work seemed to be highly standardised across the various types of laboratories across Europe. On average, standard operating procedures (SOPs) were available in approximately $90 \%$ of all hospitals. At the department level, availability of clinical guidelines or protocols was significantly less common. In summary, guidelines were available for the management of patients with AMI (mean $=86.7 \%$ ), appendicitis (mean $=54.3 \%$ ), or obstetrical problems such as breech presentation (71.5\%) and vaginal birth after caesarean delivery (64.5\%). Between-country variation for the availability of clinical or practice guidelines was limited for hospital-wide guidelines and SOPs, but substantial for condition-related, department-level guidelines (table 5).

\section{Ol strategy 5: Performance indicators or measures}

For the three medical conditions included in this study, hospitals were asked to report the availability of performance data for a selection of clinical indicators. Table 6 shows the findings. In summary, the availability of AMI performance data was most complete, averaging approximately $70 \%$ for the seven selected indicators. Poland reported the highest percentages, France the lowest. Performance data on the management of appendicitis were being collected for approximately $50 \%$ of the five indicators, varying from $42 \%$ for perforated appendicitis treated surgically $24 \mathrm{~h}$ after admission to $68.2 \%$ for wound infections. The Czech Republic and Poland performed best in this area. Lastly, the statistics for obstetrical indicators varied from $54.0 \%$ for the rate of vaginal birth after caesarean delivery to $85.3 \%$ for the percentage of caesarian deliveries. Obstetrical data were most complete in Poland and Belgium, and least complete in Ireland (table 6).
Ol strategy 6: Internal audit, assessment of clinical standards

Medical staff performance was systematically reviewed at 50\% of the participating hospitals, and peer review (site visits) was conducted at approximately $25 \%$. Between-country variations were considerable. Belgium, Poland and the Czech Republic reported that over $60 \%$ of the hospitals performed medical staff performance reviews, versus $26.1 \%$ of Irish hospitals. However, Irish hospitals made more use of peer review (site visits) than any other European country (39.1\%).

On average, $50 \%$ of the laboratories at European hospitals were periodically surveyed by an internal audit team. Percentages varied according to the type of laboratory and between countries. France reported generally low rates; in Poland internal auditing seemed broadly implemented. However, only a third of the Polish hospitals reported the results of internal audits to their governing boards, versus approximately $90 \%$ of the hospitals in the Czech Republic and Ireland. Polish hospitals more openly shared the results with their medical staffs (59.2\%), but other countries reported higher percentages. Belgium was the exception here: only $40 \%$ disclosed their results to medical staff (table 7).

\section{Ol strategy 7: External assessment}

Most hospitals (88\%) have been assessed (at least in part) by an external organisation such as an accreditation $(59.4 \%)$ or certification (49.4\%) institute, a patient organisation (18.5\%), or a government inspection body (66\%). Some hospitals were audited by more than one organisation. In Spain, for instance, $64.8 \%$ of all hospitals $(n=88)$ reported being evaluated by an accreditation body, and $63.6 \%$ by a certification institute. In France $(n=63), 93.7 \%$ of all hospitals had been accredited, and in Ireland $(n=22) 90.9 \%$. In Poland $(n=75)$, government inspections were the most frequently reported type of external evaluation (76\%).

French hospitals reported being most open (92.3\%), and Spanish hospitals the least open (19.8\%) about their assessment results. On average, $52.9 \%$ of the hospitals in our sample publicly disclosed their assessment results (table 8). Most participating hospitals $(84.3 \%)$ reported plans for re-evaluation within the next 3 years (not shown). Accreditation bodies were listed most frequently as the future assessors; in the Czech Republic, Ireland, the UK, and the Netherlands, more than $85 \%$ of the hospitals expressed this intention, and the figures were $78.1 \%$ for France and $77.3 \%$ for Spain.

Table 8 Quality improvement (0I) strategies as applied in European hospitals: external assessment, schemes and programmes; total and per country*, numbers are positive responses in valid percentages (total item response in absolute numbers)

\begin{tabular}{|c|c|c|c|c|c|c|c|}
\hline Specification of 0 l strategy & Total & Ireland & Belgium & France & Spain & Poland & Czech Republic \\
\hline (Part of) hospital previously externally assessed & $88.0(351)$ & $100(23)$ & $95.8(24)$ & $96.9(65)$ & $85.8(106)$ & $82.9(76)$ & $71.8(39)$ \\
\hline \multicolumn{8}{|l|}{ External assessment by: } \\
\hline Accreditation institute & $59.4(323)$ & $90.9(22)$ & $20.8(24)$ & $93.7(63)$ & $64.8(88)$ & $35.5(76)$ & $29.4(34)$ \\
\hline Certification institute & $49.4(314)$ & $60.0(20)$ & $41.7(24)$ & $23.3(60)$ & $63.6(88)$ & $48.6(72)$ & $48.6(37)$ \\
\hline Patient/consumer organisation & $18.5(297)$ & $33.3(18)$ & $34.8(23)$ & $3.4(58)$ & $5.3(76)$ & $18.9(74)$ & $36.4(33)$ \\
\hline Inspection & $66.0(318)$ & $80.0(20)$ & $83.3(24)$ & $55.9(59)$ & $65.9(91)$ & $76.0(75)$ & $28.1(32)$ \\
\hline Public disclosure of assessment results & $52.9(331)$ & $60.9(23)$ & $33.3(24)$ & $92.3(65)$ & $19.8(91)$ & $50.6(77)$ & $67.6(34)$ \\
\hline \multicolumn{8}{|l|}{ Previous external assessment of laboratories: } \\
\hline Clinical chemistry laboratory & $68.6(303)$ & $57.1(21)$ & $76.2(21)$ & $65.2(46)$ & $59.4(96)$ & $70.8(65)$ & $81.6(38)$ \\
\hline Pathology laboratory & $38.7(261)$ & $60.9(23)$ & $19.0(21)$ & $50.0(28)$ & $34.8(92)$ & $28.6(49)$ & $35.3(34)$ \\
\hline Microbiology laboratory & $58.7(283)$ & $65.0(20)$ & $71.4(21)$ & $60.5(43)$ & $48.4(93)$ & $68.3(60)$ & $50.0(32)$ \\
\hline Pharmacy laboratory & $54.6(302)$ & $72.7(22)$ & $59.1(22)$ & $65.5(58)$ & $39.6(91)$ & $62.9(62)$ & $39.4(33)$ \\
\hline Diagnostic radiology laboratory & $56.8(294)$ & $85.0(20)$ & $60.0(20)$ & $61.2(49)$ & $47.3(93)$ & $56.5(62)$ & $60.0(35)$ \\
\hline
\end{tabular}

*The results for the UK and the Netherlands are included in the total but not listed separately, due to the very low response rates. 


\section{DISCUSSION}

This study has some limitations. The response rates varied per country, and were particularly low in the UK and the Netherlands. This may be explained by the various approaches used to recruit hospitals for the MARQuIS project, and to the effect of questionnaire fatigue due to the over-application of questionnaire surveys to evaluate healthcare performance in general. We therefore cannot rule out participation bias. Also, accuracy of the information is always a limitation when using self-reported data. However, the results of our validation process strongly suggest that the reported results are fairly accurate. Further, translation of the questionnaire, the use of jargon, and the involvement of people from various healthcare systems may have caused differences in how the items were interpreted. Lastly, hospitals may use local OI approaches or tools not included in this questionnaire, in which case the application of OI strategies, as described in this article, may misrepresent the "maturity" of hospitals' quality management systems. These limitations should be taken into account when interpreting results.

International comparisons can promote learning and the spread of good practice, and are one of the ways in which the European Community is expected to raise healthcare quality. This study of how European hospitals apply seven common OI strategies found considerable variation between the level of implementation of the different strategies - a finding that leaves considerable scope for progress in making OI a reality.

The use of OI strategies at the European level was determined or at least influenced by national and international policy making and regulation, as well as by national and local bottomup actions initiated by professionals or others..$^{35}$ In our study $88 \%$ of all hospitals reported having been externally assessed; the widespread application of the "external assessment" OI strategy can be ascribed to the fact that most countries have adopted one or more models of external assessment (ie, accreditation, certification or licensure) to ensure and improve hospital performance, which in turn has been related to financing healthcare delivery.

\section{Key messages}

- Quality improvement (0I) strategies are widely used in European hospitals. The most widely applied Ol strategy is external assessment of hospitals, whereas patient involvement in $\mathrm{Ol}$ activities is the least widely applied

- Reported implementation varies per country. This leaves considerable room for progress in making $\mathrm{Ol}$ in hospitals a reality

- Differences also suggest that, for various reasons, countries may prefer some Ql strategies over others

\section{Contribution to better patient care}

- International comparisons of the use of Ql strategies can promote learning and the spread of good practice

- The results of this study may be useful to national policy makers in monitoring the attainment of healthcare policy goals

\section{Points for further research}

Further research should focus on exploring the relationship between the use of $\mathrm{Ol}$ strategies and the actual performance of hospitals, including the relative contribution of each of the seven Ol strategies to performance
However, policies and regulations may not always be effective, as shown by the fact that in most hospitals (>90\%), patient involvement in OI activities was lacking. This was despite the various legal and other efforts undertaken by the European Commission over the past decades to increase citizens' participation in OI, and in the organisation and structure of health services in general. ${ }^{45}$ Future research should focus on detecting barriers to the implementation of these OI strategies. In this regard, efforts by the $\mathrm{EU}$ to facilitate improvements and foster European collaboration may help to further increase implementation. ${ }^{36}{ }^{37}$

Legislation recently proposed by the European Commission stresses the values and principles of safe, high-quality health services that underpin European health systems. However, the question arises as to how these agreed-upon values and principles can be applied by member states. ${ }^{36}$ We believe our results may help national policy makers to monitor the attainment of healthcare policy goals. The application of more OI strategies, however, may not necessarily imply more positive effects on performance. Our findings would be even more valuable if the demonstrated use of OI strategies could be related to actual performance in hospitals. This would give EU policy makers direct input for monitoring the development of healthcare policies and regulations. Elsewhere in this supplement this relationship is explored in greater depth.

Acknowledgements: The authors wish to thank the European Commission for funding this research, and all those who supported and guided this work both within the MAROulS project team and as external associates. In particular we like to thank all the country coordinators for their valuable comments: B Kutryba (Poland), J Bañeres (Spain), P Doets and H Beaard (the Netherlands), C Bruneau and F Bousquet (France), A Jacquerye and A Vleugels (Belgium), I Stanek, S Zamarian and V Typovska (Czech Republic), H Crisp and A Cassell (UK), and E O'Connor (Ireland). We also express special thanks to the medical specialists who provided knowledgeable comments and suggestions on condition-specific questions: FJL Reijnders (Slingeland Hospital, Doetinchem, the Netherlands), GP Gerritsen (Tweesteden Ziekenhuis, Tilburg, the Netherlands) and AAM Wilde (Academic Medical Center, Amsterdam, the Netherlands). Lastly, we thank all the MARQulS research and project partners for their continuing collaboration in this questionnaire survey: B van Beek, P Garel, 0 Groene, K Hanslik, P Poletti, C Shaw, E Spencer and K Walshe.

Funding: Research done for the "Methods of Assessing Response to Quality Improvement Strategies (MARQulS)" project (SP21-CT-2004-513712) was funded by the European Commission through its Scientific Support to Policies action under the Sixth Framework Programme for Research.

Competing interests: None declared.

\section{REFERENCES}

1. European Court of Justice. Case C-158/96; Raymond Kohll v Union des Caisses de Maladie. 28 April 1998.

2. European Court of Justice. Case C-120/95; Nicolas Decker v Caisse de Maladie des Employes Prives. 28 April 1998.

3. Kanavos P, McKee M, Richards T. Cross border health care in Europe. BMJ 1999;318:1157-8.

4. Spencer E, Walshe K. Health Care Quality Strategies in Europe. A survey of quality improvement policies and strategies in health care systems of member states of the European Union. Dec 2005, MARQulS, project no. 513712.

5. Spencer $\mathbf{E}$, Walshe K. Strategies: literature and interview summary. Quality Improvement Strategies in Healthcare systems of the European Union. April 2005. MARQulS, project no. 513712.

6. Wagner C, De Bakker DH, Groenewegen PP. A measuring instrument for evaluation of quality systems. Int J Oual Health Care 1999;11:119-30.

7. Groene $\mathbf{0}$, Jorgensen SJ. Health promotion in hospitals - a strategy to improve quality in health care. Eur J Pub Health 2005;15:6-8.

8. Shortell S. Implementation survey II, Quality management section. Berkeley, CA, USA: Health Policy and Management, School of Public Health, University of California, 1992.

9. Meurer S, McGartland D, Counte M, et al. Development of a Healthcare Quality Improvement Measurement Tool. Hosp Topics 2002;80:7-13.

10. Ovretveit J. What are the best strategies for ensuring quality in hospitals? WHOHEN, 2003. 
11. World Health Organization/International Society for Quality in Health Care Quality and accreditation in health care services. A global review. Evidence and Information for Policy, Department of Health Service Provision. Geneva: World Health Organization, 2003

12. Franco LM, Silimperi DR, Veldhuyzen van Zanten $T$, et al. Sustaining quality of healthcare: institutionalization of quality assurance. Bethesda, MD: Center for human services, Quality Assurance Project, 2002, Sept:viii, 52 (QA Monograph/USAID Contract No. HRN-C-00-96-90013).

13. Avedis Donabedian Foundation. Health Quality Service, UK. Analysis of main contents on European Accreditation systems. Scientific support report I. Marquis project. Barcelona: Avedis Donabedian Foundation, 2005.

14. JCl accreditation standards for hospitals. Chicago, IL: Joint Commission, 2003.

15. Suñol R, Garel P, Jacquerye A. Cross-border care and healthcare quality improvement in Europe: the MARQulS research project. Qual Saf Health Care 2009;18(Suppl I):i3-7.

16. Bradley EH, Herrin J, Mattera JA, et al. Quality improvement efforts and hospita performance. Rates of beta-blocker prescription after acute myocardial infarction. Med Care 2005;43:282-92.

17. Organisation for Economic Co-operation and Development (OECD). Lambie L, Mattke $S$ and the Members of the OECD Cardiac Care Panel. Selecting indicators for the quality of cardiac care at the health systems level in OECD countries. OECD health technical papers no. 14. Paris: Directorate for Employment, Labour and Social Affairs, 2004.

18. Mehta RH, Montoye CK, Faul J, et al. Enhancing quality of care for AMl: shifting the focus of improvement from key indicators to process of care and tool use. J Am Coll Cardiol 2004;4312:2166-73

19. French WJ. Trends in acute myocardial infarction management: use of the National Registry of Myocardial Infarction in quality improvement. Am J Cardiol 2000;85:5-10.

20. Mehta RH, Das S, Tsai $\Pi$, et al. Quality improvement initiative and its impact on the management of patients with acute myocardial infarction. Arch Intern Med 2000; 160:3057-62.

21. Allison JJ, Catarina IK, Weissman NW, et al. Relationship of hospital Teaching status with quality of care and mortality for Medicare patients with acute myocardial infarction. JAMA 2000;284:1256-62.

22. Sloan FA, Trogdon JG, Curtis $\mathrm{LH}$, et al. Does the ownership of the admitting hospital make a difference? Outcomes and process of care of Medicare beneficiaries admitted with acute myocardial infarction. Med Care 2003;41:1193-205.
23. Guller U, Hervey S, Purves $\mathrm{H}$, et al. Laparoscopic versus open appendectomy: outcomes comparison based on a large administrative database. Ann Surg 2004;239:43-52.

24. Rosen MP, Siewert B, Sands DZ, et al. Value of abdominal CT in the emergency department for patients with abdominal pain. Eur Radiol 2003;13:418-24.

25. Terasawa T, Blackmore CC, Bent S, et al. Systematic review: computed tomography and ultrasonography to detect acute appendicitis in adults and adolescents. Ann Int Med 2004;141:537-46.

26. Blomqvist PG, Andersson RE, Granath F, et al. Mortality after appendectomy in Sweden, 1987-1996. Ann Surg 2001;233:461-2.

27. Simpson KR. Failure to rescue: implications for evaluating quality of care during labor and birth. J Perinat Neonatal Nurs 2005;19:24-34

28. Martel MJ, MacKinnon CJ, Clinical Practice Obstetrics Committee, Society of Obstetricians and Gynaecologists of Canada. Guidelines for vaginal birth after caesarean section. J Obstet Gynaec Can 2005;27:164-88.

29. De Jonge A, Lagro-Janssen AL. Birthing positions. A qualitative study into the views of women about various birthing positions. J Psychosom Obstet Gynaecol 2004:25:47-55.

30. Tsen LC. What's new and novel in obstetric anesthesia? Contributions from the 2003 scientific literature. Int J Obstet Anesth 2005;14:126-46.

31. Vendittelli F, Pons JC, Lemery D, et al. The term breech presentation: neonatal results and obstetric practices in France. Eur J Obstet Gynecol Reprod Biol 2006;125:176-84.

32. Shaw C, Kutryba B, Crisp H, et al. Do European hospitals have quality and safety governance systems and structures in place? Qual Saf Health Care 2009;18(Suppl I): $: 51-6$.

33. Fleiss JL. The measurement of interrater agreement. In: Fleiss JL, ed. Statistical methods for rates and proportions. New York: John Wiley \& Sons; 1981:212-36.

34. Spencer E, Walshe K. National quality improvement policies and strategies in European healthcare systems. Qual Safety Health Care 2009;18(Suppl I):i22-7.

35. Legido-Quigley $\mathbf{H}$, McKee M, Walshe $\mathrm{K}$, et al. How can quality of health care be safeguarded across the EU? BMJ 2008;336:920-23.

36. McKee M, Belcher P. Cross border health care in Europe. BMJ 2008;337;a610

37. Brand $\mathbf{H}$, Hollederer $\mathrm{A}$, Wolf $\mathrm{U}$, et al. Cross border health activities in the Euregios: good practice for better health. Health Policy 2008;86:245-54. 